\title{
PAPEL DO SUPERVISOR ESCOLAR DIANTE DA RELAÇÃO PROFESSOR-ALUNO
}

\section{THE RELATIONSHIP BETWEEN TEACHING SUPERVISION WITH TEACHERS AND STUDENTS}

\author{
Marlons Lino da CRUZ ${ }^{1, *}$, Antonio Marcos de Oliveira SIQUEIRA ${ }^{2}$ \\ 1,"Universidade Federal de Viçosa, DEQ, Viçosa, MG, Brasil, marlonsengprod@gmail.com \\ ${ }^{2}$ Universidade Federal de Viçosa,, DEQ, Viçosa, MG, Brasil, antonio.siqueira@ufv.br
}

\author{
ARTICLE INFO \\ Article history: \\ Received 2018-01-03 \\ Accepted 2018-05-02 \\ Available online 2018-12-21
}

Palavras-chave: Aluno. Professor. Relações. Supervisor.

Keywords: Student. Motivation factor. Teaching supervision.

RESUMO. A preocupação básica deste estudo é refletir sobre o papel do supervisor escolar diante da relação professor/aluno, relação esta que se faz imprescindível para que o processo educativo aconteça. Este artigo tem como objetivo analisar a importância de um bom relacionamento entre professores e alunos no processo de construção do conhecimento. Realizou-se uma pesquisa bibliográfica considerando as contribuições de diversos autores, procurando enfatizar a importância do bom convívio entre educando e educadores, bem como a necessidade do pedagogo cuidar para que a dimensão interpessoal entre ensinantes e aprendentes não interfira de modo negativo no processo ensino-aprendizagem. Concluiu-se a importância de ter um supervisor escolar atuando como mediador dos afetos que ocorrem no interior da escola, de modo a garantir que o processo educativo formal aconteça com qualidade.

\begin{abstract}
The basic concern of this study is to reflect on the role of the school supervisor regarding the teacher / student relationship, which is essential for the educational process to happen. This article aims to analyze the importance of a good relationship between teachers and students in the process of knowledge construction. A bibliographic research was carried out considering the contributions of several authors, trying to emphasize the importance of the good coexistence between educating and educators, as well as the necessity of the pedagogue to take care that the interpersonal dimension between teachers and learners does not negatively interfere in the teaching process. learning. It was concluded the importance of having a school supervisor acting as a mediator of the affections that occur within the school, in order to ensure that the formal educational process happens with quality.
\end{abstract}

\section{INTRODUÇÃO}

O presente trabalho tem como tema o papel do supervisor escolar frente às relações pessoais existentes na escola, principalmente aquela que se dá entre as duas personalidades mais importantes no desenrolar-se do processo ensino-aprendizagem, o professor e o aluno.

Nesta perspectiva, construiu-se questões que nortearam este trabalho: 
- $\quad$ As relações afetivas estabelecidas entre professor e aluno interferem no processo ensino- aprendizagem?

- $\quad$ Qual deve ser a colaboração do pedagogo frente aos impasses relacionados à interação professor-aluno a fim de proporcionar elementos que favoreçam

o sucesso do ensino-aprendizagem?

Quando se fala em processo de interação pressupõem-se os estímulos trocados entre os sujeitos nas relações sociais desencadearão em comportamentos negativos ou positivos. Daí a importância de se investigar o papel das relações entre professores e alunos no decorrer do processo ensino-aprendizagem e o papel do supervisor escolar diante de possíveis embates na ocorrência desse encontro.

Vários autores conceituam a interação como a ação mútua entre duas ou mais coisas ou pessoas, na condição de estímulos trocados entre si, com a influência do ambiente físico e social, sobre as capacidades físicas e intelectuais do indivíduo e sua ação sobre o ambiente, permitindo a formação e o desenvolvimento do ser humano.

Conforme Tassoni,

Toda aprendizagem está impregnada de afetividade, já que ocorre a partir das interações sociais, num processo vincular. Pensando, especificamente, na aprendizagem escolar, a trama que se tece entre alunos, professores, conteúdo escolar, livros, escrita, etc. não acontece puramente no campo cognitivo. Existe uma base afetiva permeando essas relações. (TASSONI, s.d., p. 3)

Neste contexto, o objetivo primordial deste estudo é, pois, investigar como deve ser a postura do supervisor frente às interações que ocorrem na escola, essencialmente entre professor e aluno.

Para alcançar os objetivos propostos, utilizou-se como recurso metodológico, a pesquisa bibliográfica, realizada a partir da análise pormenorizada de materiais já publicados na literatura e artigos científicos divulgados no meio eletrônico. O texto final foi fundamentado nas ideias e concepções de autores como: Dóron (1998) Freire (1997), Férnandez (1991), Gadotti (1999), Placco (2002), Pilleti (1999), Rego (1996), Silva (2010), Tassoni (s.d.) e Zibermam (2000).

\section{Relação supervisor-professor-aluno}

A educação é fator preponderante no processo de formação de qualquer sociedade, $\mathrm{e}$ a escola, por sua vez, enquanto instituição educativa desempenha um papel primordial no desenvolvimento de qualquer sujeito e oferece perspectivas para a ampliação da cidadania de um povo, sendo palco de diversas interações. 
A interação com outras pessoas é uma característica da vida humana, pois, desde que nasce a criança se relaciona com outros semelhantes, adultos ou crianças, formando vínculos afetivos e sociais, influenciados por valores culturais de seu contexto.

O termo interação é bastante antigo e é utilizado nas mais variadas ciências designando as relações e influências mútuas entre duas ou mais pessoas, dois ou mais fatores, sujeitos ou entes. Assim, a interação significa uma relação recíproca onde cada fator é capaz de alterar o outro, a si próprio e também a relação existente entre eles.

$\mathrm{Na}$ escola, que é a instituição responsável pela transmissão formal e sistemática do conhecimento, as interações pessoais acontecem de várias maneiras e envolvem todos os participantes da comunidade escolar, aluno-aluno, professor-professor, professor-pais, alunoprofessor, e outros, sendo, pois, um fator que merece a atenção especial do supervisor pedagógico, já que a forma como as pessoas interagem entre si estão intimamente associadas aos avanços ou retrocessos do projeto educativo da escola.

Doron (1998, p. 439), assim conceitua interação:

[...] processo interpessoal pelo qual indivíduos em contato modificam temporariamente seus comportamentos uns em relação aos outros, por uma estimulação recíproca contínua. A interação social é o modo comportamental fundamental em grupo.

De forma simples e concisa pode-se dizer que interação consiste na ação mútua entre duas ou mais coisas ou pessoas, na condição de estímulos trocados entre si, com a influência do ambiente social.

Férnandez, (1991, p. 131) comenta que "são as relações sociais, com efeito, as que marcam a vida humana, conferindo ao conjunto da realidade que forma seu contexto (coisas, lugares, situações, etc.), um sentido afetivo."

Sendo a educação uma das fontes mais importantes do desenvolvimento e agregação de valores na espécie humana, e a escola a instituição responsável pela transmissão formal e sistemática dos conhecimentos acumulados, as interações se fazem presente também nesta organização.

As relações de interação e influências acontecem em todos os momentos, no âmbito da educação sistemática, e a forma como se dão as interações na escola são de suma importância para o bom êxito dos processos educativos, afinal a escola é um ambiente que propicia as mais variadas vivências e conflitos.

O supervisor escolar desempenha importante papel nas relações de trabalho que se processam na escola, e dentre outras tarefas, é o responsável pela mediação das relações e 
dos conflitos entre professores e alunos, visando, sobretudo, o sucesso do educando frente aos objetivos educacionais.

Assim, o supervisor como um dos líderes e articuladores da escola, deve esforçar-se para que no cotidiano da sala de aula se estabeleçam vínculos de interação que garantam o êxito do processo ensino aprendizagem.

Segundo Ziberman (2009), a ideologia relativa ao processo de ensino-aprendizagem, e a sua orientação pedagógica geram implicações imediatas no rendimento educacional e na formação da personalidade dos alunos.

Logo, a interação entre professor e aluno influenciam no processo de aquisição do conhecimento, e dependem, essencialmente, de como o professor conduz a relação, a convivência com seus alunos, fato que não pode passar desapercebido dentro da escola, afinal é o sucesso do processo ensino-aprendizagem o centro de interesse da instituição escolar.

No caso específico do processo ensino-aprendizagem escolar, e do relacionamento professor/aluno as inter-relações despertam a existência de vínculos afetivos, o que aproxima, ou não, o aluno do professor e consiste em um fator auxiliar na mediação do conhecimento.

A relação estabelecida entre professores e alunos constitui o cerne do processo pedagógico e muitas vezes, desencadeia a maioria dos problemas existentes no dia-a-dia da escola.

Nesse sentido mostra-se necessário, e essencial, que o supervisor crie um espaço para refletir com os professores e alunos sobre o tipo de relações que são vivenciadas dentro da sala de aula.

Neste contexto, percebe-se que a importância das relações pessoais na escola esbarra necessariamente na relação entre professor aluno, cabendo ao supervisor se atentar especificamente nesta questão cujo resultado atinge predominantemente o processo ensinoaprendizagem, foco principal de todo educandário, e dessa forma alvo da atenção do trabalho pedagógico. Afinal, é no cenário da sala de aula que se estabelecem as mais importantes relações da escola, e é nesse ambiente que o conhecimento é estruturado. Piletti (1999, p.131), defende que numa sala de aula, a relação com outros seres humanos influencia mutuamente os indivíduos, sendo que "o professor exerce influência sobre os alunos e estes sobre o professor e os colegas."

A escola é um espaço de trabalho, e de construção do conhecimento onde as chances de sucesso ou fracasso dependem muito da qualidade da relação entre educador e educando. $\mathrm{Na}$ escola, o conhecimento é estruturado na interação do sujeito com o meio, do sujeito com o objeto de conhecimento e principalmente do sujeito com outros sujeitos.

Nesta perspectiva, constata-se que a relação estabelecida entre professores e alunos constitui a essência do processo pedagógico. 
O processo de aprendizagem ocorre em decorrência de interações sucessivas entre as pessoas, a partir de uma relação vincular, [...] e é através do outro que o indivíduo adquire novas formas de pensar e agir e, dessa forma apropria-se (ou constrói) novos conhecimentos. (TASSONI, 2010, p.6).

Obviamente, o professor é influenciador imediato do aluno em sala de aula. Muitos dos problemas enfrentados em nossas escolas provêm de várias situações sócio-afetivas não resolvidas e da debilitação que muitas crianças passam a ter, causando, muitas vezes, conseqüências irreversíveis na escola.

$\mathrm{Na}$ escola, através dos relacionamentos estabelecidos, o aluno tem oportunidade de ampliar as referências para o seu desenvolvimento emocional, intelectual, social, e é o professor quem interage intensamente com ela.

No processo de interação professor-aluno não há como negar a influência do professor no comportamento ou no desempenho cognitivo dos alunos. A influência é positiva quando predomina nos diálogos, a afeição, o respeito, a valorização aos conhecimentos e sentimentos dos alunos. Por outro lado, a influência é negativa quando observa-se na relação sentimentos de rejeição, indiferença, autoritarismo, crítica aos conhecimentos e comportamentos dos alunos ocasionando atitudes de tensão, agressividade e desinteresse e consequentemente a possibilidade de fracasso escolar. Sobre a convivência entre professor e aluno, Placco (2002, p.9), alega que a qualidade da interação estabelecida é fundamental para que a "construção e transformação cognitivo-afetivo-social de cada um dos parceiros ocorram na direção do pleno desenvolvimento de ambos como pessoas.". Placo (2002, p.11), enfatiza ainda, que "há um sentido de parceria e cumplicidade nessa troca interpessoal" o que possibilita a construção e a transformação do conhecimento.

Conforme, já comentado, anteriormente, professor e aluno representam a razão de ser do processo ensino-aprendizagem e o foco central na aprendizagem é a interação existente entre ambos. Sem que haja uma convivência positiva entre estes dois sujeitos não há aprendizagem de qualidade. Gadotti (1999) afirma que na relação professor-aluno o diálogo é fator fundamental na comunicação e para praticar o diálogo o educador deve colocar-se na posição humilde de quem não sabe tudo.

Piletti (1999) considera o professor o grande responsável pelo relacionamento sadio para com os alunos. "Sua influência na sala de aula é muito grande, e a criação de um clima psicológico que favoreça ou desfavoreça á aprendizagem depende principalmente dele". (PILETTI, 1999, p.250). 
Quando na relação professor-aluno há predominância do controle, da ameaça e da punição por parte do professor, as reações dos alunos serão de rebeldia e provocação, como se estivesse vivendo um enfrentamento contínuo de forças. Rego (1996), defende que se o professor faz questão de impor demasiadamente sua autoridade perante seus alunos não conseguirá alcançar resultados proveitosos em seu trabalho, mas sim irá impor sua vontade, estabelecendo uma relação baseada no medo, provocando "reações diferentes das inspiradas por princípios democráticos". (REGO, 1996, p. 98).

Desse modo, se o docente trabalha procurando manter um clima de respeito, promovendo a, interação através da comunicação conseguirá contagiar os mesmos, evitando assim comportamentos de antipatia, rebeldia ou rivalidade. Nesse sentido, Araújo (1996, p. 42), afirma que se "o professor ou professora consegue estabelecer relações baseadas no diálogo, na confiança e nutrir uma efetividade que permite que os conflitos cotidianos da escola sejam solucionados de maneira democrática".

É importante que o professor reconheça e assuma seu papel de estimulador e ainda de mediador entre o aluno e o conhecimento. Ciente desse seu papel, o professor deve procurar criar condições afetivas favoráveis à aquisição, pelos alunos, de conhecimentos socialmente acumulados. Silva (2010) destaca que cabe ao professor agir como intermediário entre os conteúdos da aprendizagem e a atividade construtiva para assimilação.

A relação professor aluno é importante para o processo ensino aprendizagem, cabendo ao professor utilizar estratégias em diversas situações para propiciar situações de conversa, brincadeiras, aprendizagens orientadas de forma que possam comunicar-se e expressar-se, criando um ambiente acolhedor, de confiança e auto-estima.

Um relacionamento sadio entre professor e aluno onde respeito-mútuo, companheirismo, bom-humor e partilha estão presentes, é fundamental para entendimento e apreensão dos conteúdos. Assim uma situação de aprendizagem num clima saudável proporciona maior assimilação dos conteúdos, e uma convivência conflituosa dificulta a assimilação dos mesmos. No entanto, Freire afirma que:

O professor autoritário, o professor licencioso, o professor competente, sério, o professor incompetente, irresponsável, o professor amoroso da vida e das gentes, o professor mal-amado, sempre com raiva do mundo e das pessoas, frio, burocrático, racionalista, nenhum deles passa pelos alunos sem deixar sua marca. (FREIRE, 1996, p.73). 
Diante destes pressupostos, necessário se faz, que o supervisor pedagógico, enquanto facilitador das relações na escola, esteja sempre atento às interações existentes entre professores e alunos, criando situações que levem o educador a avaliar sua prática, bem como propiciando momentos de formação em serviço, de modo que o professor tenha a oportunidade de fundamentar seu fazer educativo, buscando uma aproximação com seus alunos. Propiciar que o educador pense sobre a interação professor-aluno pode constituir-se para o mesmo num subsídio de reflexão sobre os procedimentos que utiliza em sala de aula, favorecendo a formação da autocrítica e o julgamento da prática pedagógica que realiza, ferramentas fundamentais para que consiga fazer melhor o dia a dia dos alunos na escola e consequentemente o aprender.

\section{CONSIDERAÇÕES}

Diante do exposto, concluiu-se que a interação existente entre professor e aluno, é um dos componentes mais importantes para o sucesso do ensino-aprendizagem. Sem que haja uma convivência positiva entre estes dois sujeitos não há aprendizagem de qualidade.

O supervisor enquanto agente formador e gerenciador dos processos de aprendizagem dentro da escola, torna-se o responsável por cuidar para que no cotidiano da instituição, as manifestações de interação colaborem para o alcance dos objetivos educacionais, cabendo a ele, inclusive, mediar as relações entre professores e alunos, que nem sempresão satisfatórias

Dessa forma constatou-se que o supervisor escolar, em seu trabalho de líder e articulador deve interpretar e analisar os conflitos e tensões do universo escolar, mas preocupando-se sobremaneira, com as relações estabelecidas entre professor e aluno, já que estas interferem substancialmente no processo ensino-aprendizagem, alvo do trabalho pedagógico.

Nesse ínterim, cabe ao supervisor escolar zelar para o bom convívio entre professor e aluno, se interpondo entre possíveis conflitos entre ambos, e principalmente criando estratégias que propiciem ao professor compreender e se conscientizar do importante papel das relações para o processo de construção da aprendizagem, de modo que estabeleçam com os alunos uma relação empática de com vistas a otimizar os resultados educacionais. 


\section{REFERÊNCIAS}

DORON, Roland. Dicionário de psicologia. São Paulo: Ática, 1998.

FERNANDÉZ, Alícia. A inteligência aprisionada. Porto Alegre: Artes Médicas, 1991.

FREIRE, P. Pedagogia da autonomia: saberes necessários à prática educativa. São Paulo:

Paz e Terra, 1997.

GADOTTI, Moacir. Convite à leitura de Paulo Freire. São Paulo: Scipione, 1999.

PILETTI, Nelson. - Psicologia Educacional. Série Educação. São Paulo - São Paulo. Ática. 1999.

PLACCO, Vera Maria Nigro de Souza \& ALMEIDA, Laurinda Ramalho. As Relações Interpessoais na Formação de Professores. São Paulo: Loyola, 2002.

REGO, Teresa Cristina. A indisciplina e o processo educativo: uma análise na perspectiva Vygotskyana. In: Júlio Groppa. Aquino (Org.) Indisciplina na Escola: alternativas teóricas e práticas. São Paulo: Summus editorial, 1996.

TASSONI, Elvira Cristina Martins. Afetividade e aprendizagem: a relação professor-aluno. Disponível em: www.anped.org.br/reunioes/23/textos/2019t.PDF. Acesso em 31 de out. de 2010. ZIMERMAN, David. E. Grupos de educação médica. In: Fundamentos básicos das grupoterapias. 2. ed. Porto Alegre: Artmed, 2000. 